\title{
Space Debris Mitigation Efforts through the Disposition of the Service Module of the Unmanned Space Experiment Recovery System (USERS)
}

\author{
By Koichi IJICHI, Atsuo USHIKOSHI, Shuji NAKAMURA, Hiroshi KANAI \\ Institute for Unmanned Space Experiment Free Flyer (USEF), Tokyo, Japan
}

(Received April 25th, 2008)

\begin{abstract}
The Unmanned Space Experiment Recovery System (USERS) Project has been completed with full success, and the Service Module (SEM) of the USERS Spacecraft, which supported the recovery portion of the spacecraft which was left on the orbit, was properly disposed to the maximum extent as possible according to the IADC debris mitigation guideline and re-entered the atmosphere on June 15, 2007 (JST). USERS spacecraft disposition by possible means available at the mission completion showed good example of realizing debris mitigation purpose in spite of originally different design baseline, and obtained actual data and experiences to be reflected for future space programs.
\end{abstract}

\section{Introduction}

The Service Module (SEM) of the USERS Spacecraft re-entered the atmosphere and was disposed properly on June 15, 2007. The decayed point was 1.2 degree $\mathrm{N}$ and 318.4 degree E, and the time was 9:16 UT (+/- 2 minutes) according to the Space Track report, which is consistent with the analysis results based on the several Two Line Elements (TLE) of the final orbit of the USERS SEM.

The USERS Project has been completed with full success at February 25, 2005, and the SEM was disposed to the maximum extent as possible according to the IADC debris mitigation guideline, and its orbit decay was monitored after the disposition operation was completed on Match 11, 2005 (JST). The USERS Spacecraft was self-return unmanned space experiment system, and consisted of the Re-entry Module (REM) and the SEM, and was launched on September 10,2002 . The REM was separated from the SEM and returned to the earth with on-orbit experiment results on May 30, 2003 while the SEM kept being operated on orbit with its own mission till end of January 2005. The SEM disposition at the end of the mission was not considered at the design phase, but fortunately the SEM has capability to change orbit, moreover, the residual propellant was enough to lower the orbit and to set the attitude adequate for the SEM to enter the atmosphere within 25 years. The SEM disposition operation was performed according to the guideline as much extent as possible.

USERS Project has been promoted by the Ministry of Economy, Trade and Industry (METI) and the New Energy and Industrial Technology Development Organization (NEDO), and developed and operated by the Institute for Unmanned Space Experiment Free Flyer (USEF), to establish an unmanned on-orbit experiment infrastructure. USEF is a nonprofit organization founded by 13 Japanese space related companies in 1986 to promote the industrialization and utilization of the space.

\section{The Outline And The Results Of The USERS Project}

The USERS Project has been proposed and authorized on following objectives on Japan Fiscal Year (JFY) of 1996.

1) To establish the unmanned space experiment system with self return capability.

2) To perform Super-conductive Material Processing Experiment (SMAP) on the orbit, and return the results.

3) To verify commercially available parts and technologies on the low earth orbit.

The USERS Spacecraft consists of the SEM and the Reentry Module (REM) as shown in Fig.1. The REM consisted of the Recovery Vehicle (REV), which is recovery capsule of the Spacecraft, and the Propulsion Module (PM), which was installed with the retro-boost motor for the return. The experiment furnaces to perform the second objective was installed in the REV. The REM was separated from the SEM, and the REV reached the ground, and was recovered. The SEM provided various services such as communication between mission payload and the ground, electric power necessary for the experiment operation, etc. for the REM. The USERS spacecraft attitude and the orbit were also controlled by the SEM. After the mission experiment operation completed, the orbit adjustment toward REM return will be performed. And finally, the REM was separated and de-orbited, and splashed down in the recovery area east of the Ogasawara Islands in the Pacific Ocean. The experiments to perform the third objective were installed in the SEM system, and kept their operation after the REM return. The mission profile of the USERS Project is shown in Fig. 2.

USERS Spacecraft was launched at 5:20PM(JST) on September 10, 2002 with Data Relay Test Satellite West (DRTS-W) by H-IIA\#3 launch vehicle from Tanegashima Space Center. 


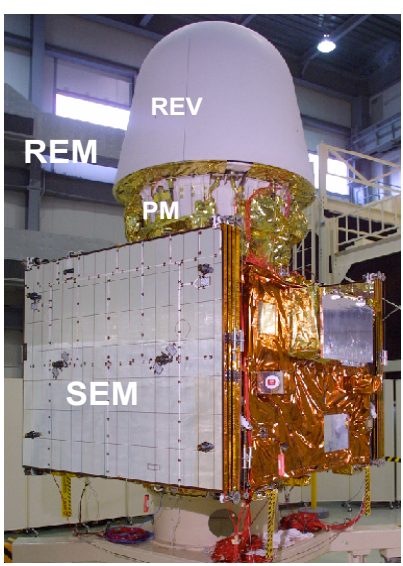

Fig.1. USERS spacecraft

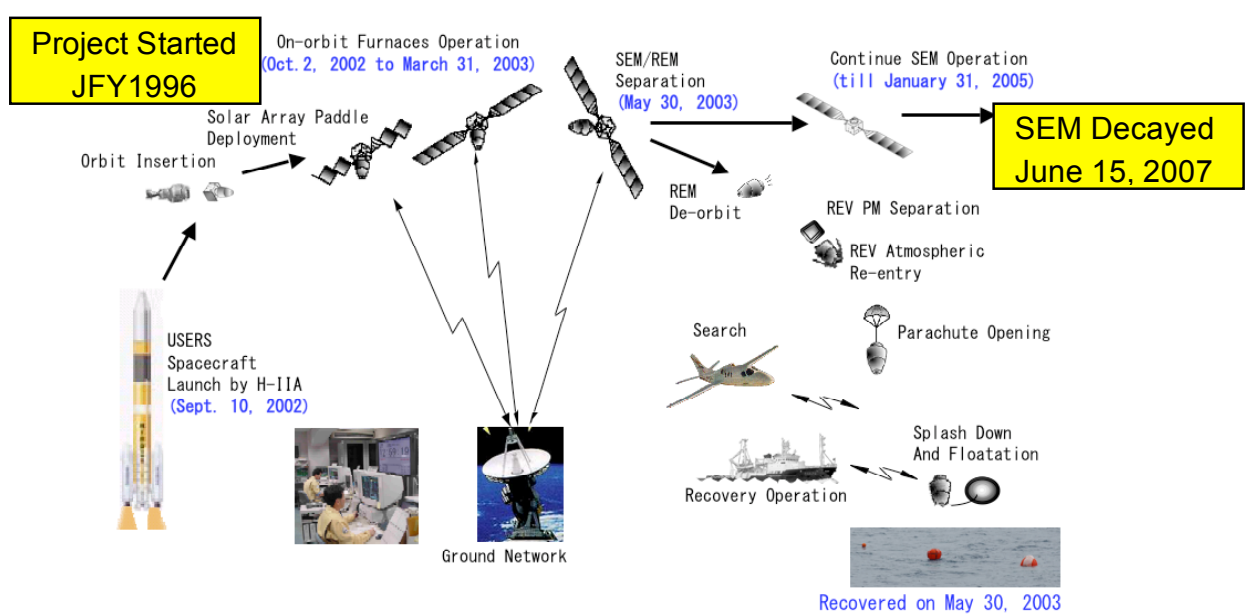

Fig. 2. Outline of the USERS mission operation
After the initial check out of the bus system and the mission equipment, the Material Processing Experiment operation has started on Oct. 2, 2002 and been completed as expected on March 31, 2003. The preparation for the return such as the orbit adjustment followed, and the REM has successfully been separated and returned to the earth at 6:23 AM (JST) on May 30, 2003, and retrieval operation completed at 9:50 AM (JST). This was the moment when the Unmanned Space Experiment Infrastructure with long duration and better micro-gravity environment capability has been established and recovered the on-orbit experiment results of the SMAP experiment. The first and the second objectives of the project were achieved.

After the REM return, the SEM orbit was raised up to 580 $\mathrm{km}$, and continued operation with its 5 kinds of Advanced bus system experiment till the end of January 2005. The purpose of the experiment is to verify commercial technologies and the parts on the space environment to reduce the cost of the spacecraft. The results were satisfactory, and leaded to the following full dressed project called Space Environment Reliability Verification Integrated System (SERVIS), and then finally, the third objective was also achieved.

As a result at the end of the mission on January 31, 2005, the USERS Project accomplished more than $100 \%$ of what have originally intended. The details of the USERS Project and its results are available through references ${ }^{1)}$ ) and the $\mathrm{URL}^{3)}$ indicated.

\section{The SEM Disposition Strategies Consideration}

The IADC Space debris mitigation guideline indicated that the following items should be executed for all spacecraft.

1. Debris mitigation measures should be taken as much as possible as:

a) Re-enter the atmosphere within 25 years

b) Estimate the ground safety by the survivability and the casualty analysis.

c) Exclude residual stored energy such as the propellant the batteries and the RWs rotations. d) Protect reactivation of the system

2. Terminate entire system including the transmitters

3. Monitor the system till the re-enter and estimate the possible time and place of the re-entry.

4. Inform the public about the decay status.

At the start point of the USERS Project, the requirements for the spacecraft design, as space debris mitigation measures, not to release any object during the operational phase including at the solar paddle deployment and at the SEM/REM separation were imposed on the system design. The disposition of the SEM positively at the end of the entire mission was excluded from the design requirement considering USERS SEM final operational orbit altitude and the amount of the propellant.

The propellant tank volume was decided considering the attitude and orbit control of the spacecraft throughout the mission with +3 sigma drag condition. In the worst condition of the atmospheric drag, the propellant might be consumed at the end of the mission.

The Total Number of Casualty Analysis based on the Reentry Survivability Analysis was approximately 0.54/10000 (less then 1/10000) based on the Global Population Distribution Database of 1996, so that the SEM was planned to be just left on the final operational orbit after appropriate measure not to break out to increase the debris such as to exhaust all the propellant and to discharge the batteries at the design phase of the project.

After the orbit raising operation of the SEM after the REM separation/return operation, the residual propellant was analyzed, and was estimated to be more than $50 \mathrm{~kg}$, which was enough to lower the orbit to reduce the time to re-enter the atmosphere, and the study work of the possible disposition of the SEM after the completion of the entire mission was started. The more positive strategies towards the Guideline were considered. The additional positive strategies were as follows. 
1. Lower the SEM orbit to reduce the time for the SEM atmospheric re-entry

2. Exhaust the residual propellant until the minimum amount which was necessary to maintain the SEM attitude.

3. The disposition period should be between February to March of the year 2005 after the all of the USERS Project planned missions were completed.

Table 1 indicated the summary of the compliance analysis with the IADC guideline including the additional measures. The residual propellant was consumed by the orbit descent except for about $15 \mathrm{~kg}$ of propellant necessary for setting the attitude rotation mode before the transmitter turn off. $\mathrm{NiH} 2$ batteries were properly tested before the integration into the spacecraft, and also properly monitored to maintain the normal condition during the operation phase. The difference from the guideline requirement is that the spacecraft kept alive with minimum capabilities to maintain the system soundly till the re-entry except for the transmitter status. The spacecraft $S$ band transmitters were turned off but the batteries were kept charged as normal operation. The details of the spacecraft configuration after the mission completed will be described later.

\section{The USERS SEM Disposition Study and The Operation}

\subsection{Selection of the controlled or uncontrolled re-entry}

For the LEO satellites, requirement to raise spacecraft orbit higher than $2000 \mathrm{~km}$ or to lower the orbit to decay within 25 years are indicated in the guideline. Possible options for the USERS SEM were summarized in Fig. 3. The disposition operation period was limited within the months of February 2005, and should be completed by March 31, 2005.
The amount of the residual propellant was far from that necessary to raise the orbit higher than $2000 \mathrm{~km}$, so that the Option A was deleted (see Table 2). The strategy decision flow chart practically adaptable for USERS Project case is for the trade off for the selection among Options from B to D.

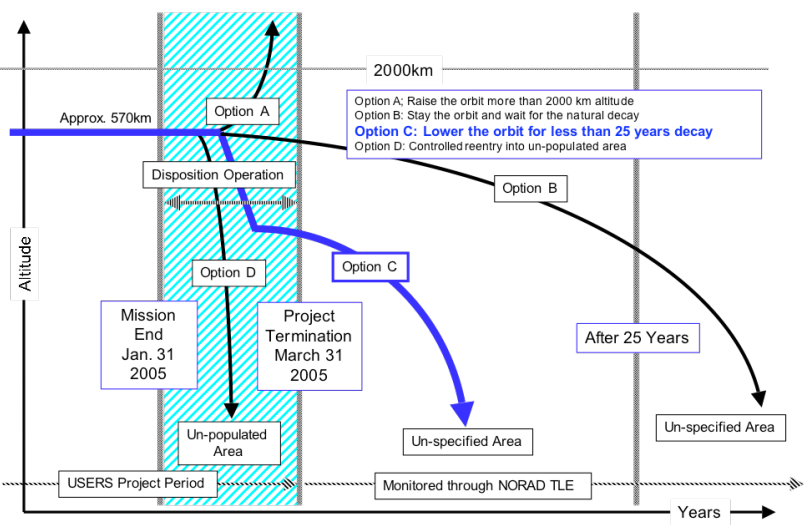

Fig.3. USERS SEM orbit disposition options

The casualty number, which was analyzed to be $0.54 / 10000$, was based on the survivability analysis of the SEM at the re-entry. The SEM was decayed from outer panel during the reentry due to the heat from the air drag. As a result of the analysis, the small amount of the paddle drive mechanism and the propellant tank would survive and reach the ground. The casualty number was calculated based on these survived materials.

This number was less than $1 / 10000$, and was the number indicated to allow uncontrolled re-entry by the guideline. As a result, the uncontrolled re-entry option was selected.

Table 1. Summary of the USERS spacecraft compliance analysis for IADC guideline

\begin{tabular}{|c|c|}
\hline IADC Space Debris Mitigation Guideline & USERS Spacecraft \\
\hline 5 Mitigation Measures & -- \\
\hline 5.1 Limit Debris Released during Normal Operations & Satisfied \\
\hline 5.2 Minimise the Potential for On-Orbit Break-ups & -- \\
\hline 5.2 .1 Minimise the potential for post mission break-ups resulting from stored energy & -- \\
\hline $\begin{array}{l}\text { (1) Residual propellants and other fluids, such as pressurant, should be depleted as thoroughly as } \\
\text { possible, either by depletion burns or venting, to prevent accidental break-ups by over-pressurisation or } \\
\text { chemical reaction }\end{array}$ & Satisfied \\
\hline $\begin{array}{l}\text { (2) Batteries should be adequately designed and manufactured, both structurally and electrically, to } \\
\text { prevent break-ups. Pressure increase in battery cells and assemblies could be prevented by mechanical } \\
\text { measures unless these measures cause an excessive reduction of mission assurance. At the end of } \\
\text { operations battery charging lines should be de-activated. }\end{array}$ & $\begin{array}{c}\text { Satisfied in battery design } \\
\text { approach } \\
\text { mission dispositions }\end{array}$ \\
\hline $\begin{array}{l}\text { (3) High-pressure vessels should be vented to a level guaranteeing that no break-ups can occur. Leak- } \\
\text { before-burst designs are beneficial but are not sufficient to meet all passivation recommendations of } \\
\text { propulsion and pressurisation systems. Heat pipes may be left pressurised if the probability of rupture } \\
\text { can be demonstrated to be very low. }\end{array}$ & $\begin{array}{c}\text { Different } \\
\text { Approach }\end{array}$ \\
\hline $\begin{array}{l}\text { (4) Self-destruct systems should be designed not to cause unintentional destruction due to inadvertent } \\
\text { commands, thermal heating, or radio frequency interference. }\end{array}$ & Satisfied \\
\hline $\begin{array}{l}\text { (5) Power to flywheels and momentum wheels should be terminated during the disposal phase. } \\
\text { (6) Other forms of stored energy should be assessed and adequate mitigation measures should be } \\
\text { applied. }\end{array}$ & Satisfied \\
\hline 5.2.2 Minimise the potential for break-ups during operational phases & Satisfied \\
\hline 5.2.3 Avoidance of intentional destruction and other harmful activities & Satisfied \\
\hline 5.3 Post Mission Disposal & Satisfied \\
\hline $\begin{array}{l}\text { 5.3.1 Geosynchronous Region } \\
\text { 5.3.2 Objects Passing Through the LEO Region }\end{array}$ & Not Applicable \\
\hline 5.3.3 Other Orbits & Satisfied \\
\hline 5.4 Prevention of On-Orbit Collisions & Satisfied \\
\hline
\end{tabular}




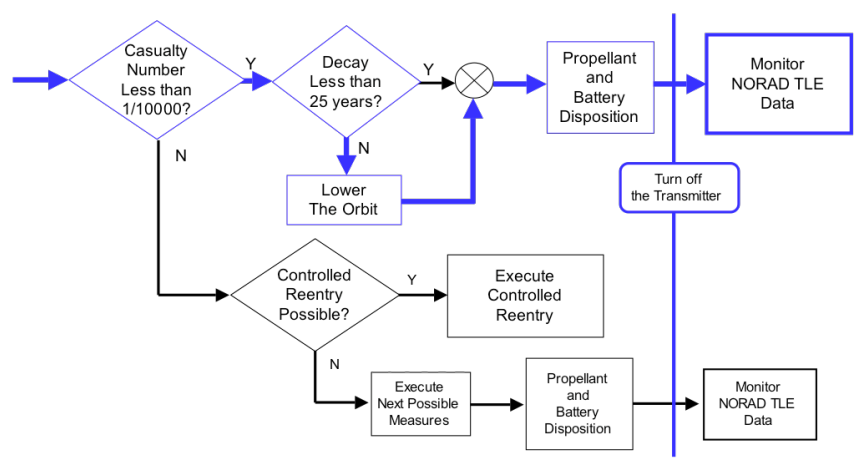

Fig.4. USERS SEM orbit disposition strategy decision flow

The orbit altitude was approximately $570 \mathrm{~km}$ at the end of the mission, so that the decay time without any orbit control, which was Option B, was analyzed to be more than 30 years. Option $\mathrm{C}$ consisted of two options depend on the amount of the orbit change as follows.

Option C1: Lower the orbit just enough for less than 25 years decay

Option C2: Lower the orbit as much as possible
There were constraints from the antenna tracking speed of the ground network, and could not track low altitude orbit such as $300 \mathrm{~km}$. The Option C2 was not selected from the standpoint of this constraint.

As the conclusion of the USERS SEM orbit disposition strategy consideration, the Option $\mathrm{C} 1$ was selected according to the decision flow in Fig. 3. The orbit of the USERS SEM was lowered from its final orbit of $570 \mathrm{~km}$ at the end of the mission to the $470 \mathrm{~km}$ orbit within the month of the February 2005. The trade off study summary is indicated in Table 2 .

\subsection{The orbit control and the propellant exhaustion operation}

The actual operation plan was established based on the strategy described in the previous paragraph. The plan mainly consisted of the orbit descent and the propellant exhaustion operation. As the result of this disposition operation, the orbit was expected to be lowered to approximately $470 \mathrm{~km}$ and the residual propellant was expected to be approximately $20 \mathrm{~kg}$. Table 3 summarized the orbit descent and exhaustion operation.

Table 2. USERS SEM orbit disposition options trade off

\begin{tabular}{|c|c|c|c|c|c|c|c|}
\hline \multicolumn{2}{|r|}{ Disposal Options } & Orbit Change & Days & \multicolumn{2}{|c|}{ Decay time } & \multirow[t]{2}{*}{ Decision } & \multirow[b]{2}{*}{ Insufficient Propellant } \\
\hline A & $\begin{array}{l}\text { Raise the orbit higher than } \\
2000 \mathrm{~km} \text { altitude }\end{array}$ & $1430 \mathrm{~km}$ Ascent & NA & & NA & & \\
\hline \multirow{3}{*}{ B } & \multirow{3}{*}{$\begin{array}{l}\text { Stay the orbit and wait for } \\
\text { the natural decay }\end{array}$} & \multirow{3}{*}{ None } & \multirow{3}{*}{ NA } & $-\sigma$ & $>30$ Years & & \\
\hline & & & & 0 & $>30$ Years & & \\
\hline & & & & $+\sigma$ & $>30$ Years & & \\
\hline C & $\begin{array}{l}\text { Lower the orbit for less than } \\
25 \text { years decay }\end{array}$ & & & & & & \\
\hline \multirow{3}{*}{ C1 } & \multirow{3}{*}{$\begin{array}{l}\text { Lower the orbit just enough } \\
\text { for less than } 25 \text { years decay }\end{array}$} & \multirow{3}{*}{$100 \mathrm{~km}$ Descent } & \multirow{3}{*}{9 Days } & $-\sigma$ & 24 Years & \multirow{3}{*}{$\begin{array}{l}\text { Selected } \\
\text { Option }\end{array}$} & \multirow{3}{*}{$\begin{array}{l}\text { Decay analysis was } \\
\text { based on least drag } \\
\text { attitude of the SEM }\end{array}$} \\
\hline & & & & 0 & 12 Years & & \\
\hline & & & & $+\sigma$ & 6 Years & & \\
\hline \multirow{3}{*}{$\mathrm{C} 2$} & \multirow{3}{*}{$\begin{array}{l}\text { Lower the orbit as much as } \\
\text { possible }\end{array}$} & \multirow{3}{*}{$291 \mathrm{~km}$ Descent } & \multirow{3}{*}{21 Days } & $-\sigma$ & 93 Days & & \multirow{3}{*}{$\begin{array}{l}\text { Ground Network could } \\
\text { not track such low orbit }\end{array}$} \\
\hline & & & & 0 & 52 Days & & \\
\hline & & & & $+\sigma$ & 28 Days & & \\
\hline D & $\begin{array}{l}\text { Controlled reentry into un- } \\
\text { populated area }\end{array}$ & Controlled Reentry & NA & & NA & & \\
\hline
\end{tabular}

Table 3. USERS SEM orbit descent and propellant exhaustion operation

\begin{tabular}{|c|l|c|c|c|}
\hline $\begin{array}{c}\text { Date(JST) } \\
\text { (February 2005) }\end{array}$ & \multicolumn{1}{|c|}{ Events } & $\begin{array}{c}\text { Orbit } \\
\text { (before) }\end{array}$ & $\begin{array}{c}\text { Orbit } \\
\text { (after) }\end{array}$ & $\begin{array}{c}\text { Residual } \\
\text { propellant }\end{array}$ \\
\hline 1st & (Start of the orbit disposition operation) & & & $53.4 \mathrm{~kg}$ \\
\hline 2nd & Test burns & $570.7 \mathrm{~km}$ & $559.7 \mathrm{~km}$ & $50.9 \mathrm{~kg}$ \\
\hline 4th & First descent burns & $559.6 \mathrm{~km}$ & $510.5 \mathrm{~km}$ & $41.7 \mathrm{~kg}$ \\
\hline 9th to 11th & (Monitor and additional mission operation) & & & \\
\hline 12th & Second descent burns & $510.6 \mathrm{~km}$ & $465.1 \mathrm{~km}$ & $34.7 \mathrm{~kg}$ \\
\hline 13th to 20th & (Monitor and additional mission operation) & & & \\
\hline 21st & $\begin{array}{l}\text { Propellant exhaution burns } \\
\text { (Out of plain burns) }\end{array}$ & $\begin{array}{c}465.0 \mathrm{~km} \\
30.423 \mathrm{deg}\end{array}$ & $\begin{array}{c}464.0 \mathrm{~km} \\
30.457 \mathrm{deg}\end{array}$ & $18.4 \mathrm{~kg}$ \\
\hline 22nd to 23rd & (Check out and setups for the termination) & & & \\
\hline 24th & Set stable Sun Acquisition Mode (SAM) & & & \\
\hline 25th & (End of the orbit disposition operation) & & & \\
\hline
\end{tabular}


Finally, at the end of the operation, the orbit altitude and the inclination were $464.0 \mathrm{~km}$ and $30.457 \mathrm{deg}$., and the residual propellant was $18.4 \mathrm{~kg}$ as expected. The most of the propellant exhaust methods have been experienced for the future spacecraft dispositions by the series of these operations. Possibility of collisions to other debris during the descent operation was analyzed, and it was found that no collision was expected. The nearest objects were three of Delta Rocket upper stages and the nearest distance was about $38 \mathrm{~km}$.

\subsection{The SEM configuration set up for the termination of the operation}

The nominal termination procedure is to disconnect charging line from the batteries and turn off the transmitters, and left on the orbit. The strategy for the SEM termination was to maintain the attitude as long as possible of the maximum drag condition for the earlier decay. To fulfill this objective, it was necessary to provide minimum power to keep bus system awake. Fortunately the USERS SEM has relatively large solar paddle to generate $2.5 \mathrm{~kW}$ power for the furnace operation, about $300 \mathrm{~W}$ of power necessary to maintain the bus system was able to be supplied even if the worst condition of the SEM attitude toward the Sun. The SEM configuration at the termination of the operation was as follows.

1) The SEM attitude

The SEM attitude was controlled in the spin-stabilized mode around the Sun pointing direction called Sun Acquisition Mode (SAM). And more, the spin rate was increased to $1 \mathrm{rpm}$ instead of the nominal $0.5 \mathrm{rpm}$ to attain better spin stabilization. The residual propellant would be consumed to maintain this attitude mode.

\section{2) Solar paddle configuration}

The solar paddles were set to the configuration shown in the Fig. 5. The paddles were tilted with angle of 45 degrees and 225 degrees toward the Sun direction respectively. This means that the surfaces of the solar cells on the two paddles were opposite to each other and tilted 45 degree toward the Sun direction. The purpose of this configuration was to generate enough power to maintain the bus system even if the spin axis would differ from the Sun or would cause tumbling after the all of the propellant have consumed.

3) Bus system configuration

Only the subsystems and the heaters necessary to maintain the SAM were turned on, and the other subsystems including the transmitters were turned off.

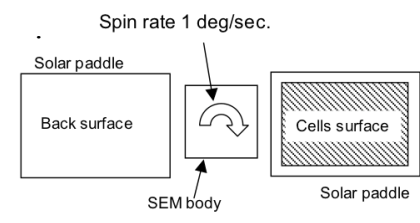

View from the Sun (Spin axis)

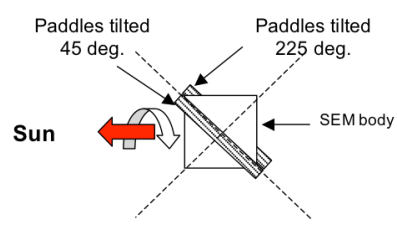

View from the paddle rotation axis
Fig.5. Solar paddle configuration at the mission termination
After all the operation necessary to terminate the USERS SEM operation, the down link transmitter was turned off finally at 9:56:52 PM (JST) on March 11, 2005.

\section{The SEM Orbit Decay And Atmospheric Re-entry Results}

The maximum collisional cross section of the SEM toward the velocity direction was $27.01 \mathrm{~m}^{2}$, which was one order of magnitude larger than the minimum cross section, $1.83 \mathrm{~m}^{2}$, which was used in the worst case decay analysis. The worst decay time was expected to be from 6 to 24 years as mentioned in previous paragraph. Considering that the attitude was expected to be maintained for a few years at least, the decay time was expected to be one half to one order of magnitude less than the worst case analysis.

The USERS SEM orbit altitude was monitored through Two Line Element (TLE) shown in the SpaceTrack WEB Site. The decay history from March 11, 2005 to June 14, 2007, a day prior to the decayed date is indicated in Fig. 6. The monitor was done once a every week, and increased when approaching the expected re-entry date.

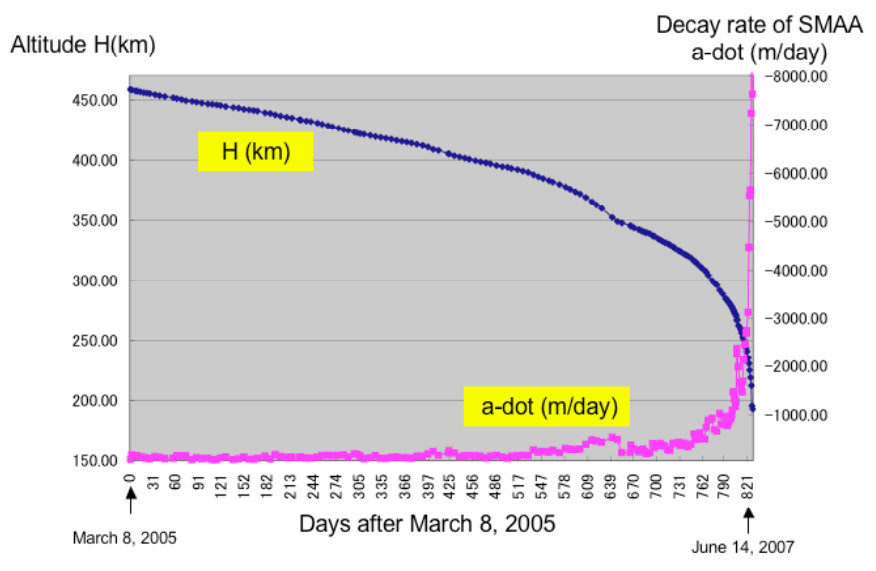

Fig.6. The USERS SEM orbit decay history

The re-entry analysis was performed 5 times using TLE of the SpaceTrack from one year to one day prior to the reentry. The analysis included the $20 \%$ of the uncertainty of the atmospheric drag force, which was affected by the solar activity and the uncertainty of the cross section of the SEM. The results of the analysis are indicated in Table 4 . The -3 to +4 days of uncertainty was remained in 2 weeks prior to the reentry analysis, and -0.2 to +0.3 day uncertainty even at a day prior to the reentry analysis. The USERS SEM was estimated to re-enter the atmosphere at $6: 16 \mathrm{PM}+2 /-2 \mathrm{~min}$. on June 15 , 2007 at the latitude of 1.2 degree $\mathrm{N}$ and the longitude of 318.4 degree E, where is $450 \mathrm{~km}$ offshore of the Brazilian coast of the Atlantic Ocean. The $20 \%$ of the uncertainty, which was supposed for our analysis, was adequate because the actual reentry date and the time were within the region of all estimated re-entry analysis uncertainty. 
Table 4. Estimated re-entry date and time

\begin{tabular}{|c|c|c|c|c|c|c|}
\hline \multirow{2}{*}{ No. } & \multirow{2}{*}{ Epoch (UTC) } & \multicolumn{3}{|c|}{ Estimated Re-entry Time (UTC) } & \multicolumn{2}{|c|}{ Error (days) } \\
\hline & & nominal & $+20 \%$ & $-20 \%$ & $+20 \%$ & $-20 \%$ \\
\hline 1 & $2006 / 02 / 10 \quad 21: 17: 49.4$ & $2007 / 03 / 18 \quad 21: 13: 23$ & $2007 / 01 / 08 \quad 05: 13: 26$ & $2007 / 06 / 23 \quad 02: 35: 25$ & -69.7 & 96.2 \\
\hline 2 & 2007/01/16 08:48:56.5 & 2007/06/19 08:13:58 & 2007/05/16 05:40:48 & 2007/07/20 13:09:49 & -31.1 & 34.1 \\
\hline 3 & $2007 / 04 / 25 \quad 20: 05: 34.5$ & 2007/06/13 13:25:29 & $2007 / 06 / 04 \quad 20: 48: 24$ & $2007 / 06 / 26 \quad 23: 20: 01$ & -8.7 & 13.4 \\
\hline 4 & $2007 / 05 / 31 \quad 13: 25: 57.3$ & 2007/06/17 16:59:56 & $2007 / 06 / 14 \quad 19: 40: 35$ & $2007 / 06 / 22 \quad 02: 23: 53$ & -2.9 & 4.3 \\
\hline 5 & $2007 / 06 / 14 \quad 06: 48: 38$ & $2007 / 06 / 15 \quad 12: 49: 34$ & $2007 / 06 / 15 \quad 07: 42: 33$ & $2007 / 06 / 15 \quad 20: 18: 41$ & -0.2 & 0.3 \\
\hline
\end{tabular}

The final orbit and the estimated decayed location is indicated in Fig. 7.

The results of the SEM decay monitor were informed to the public on June 6 and June 15 prior to the reentry, and the final SEM reentry was announced on June 18, 2007 using the Home Page of the USEF and the press release from the METI and the NEDO.

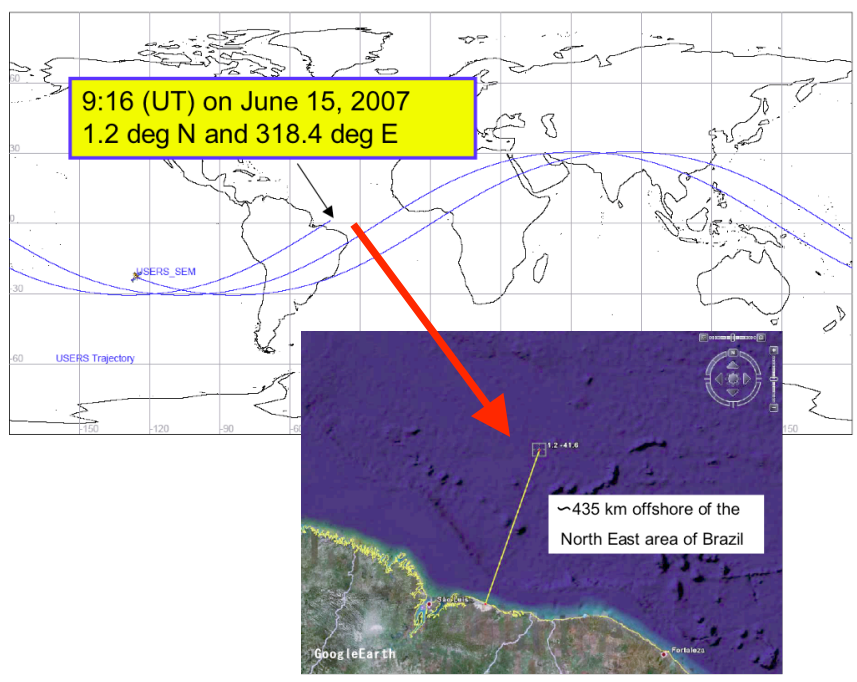

Fig.7. Estimated USERS SEM decayed location

\section{Conclusion}

The USERS SEM was properly disposed and contributed to the reduction of the space debris. The USERS SEM was not fully designed to be disposed according to the IADC Debris Mitigation Guideline at the start point of the Project on 1995, but by gathering possible means, succeeded in the almost proper disposition.

In addition to the contribution to the debris mitigation, valuable experience of the LEO spacecraft disposition has been obtained throughout this operation. And more, we felt that the discussion toward the public acceptance of the risk due to the spacecraft re-entry, which is far less than that of natural disaster whose risk is 2 to 3 orders of magnitude larger, may be necessary.
This experience will benefit the coordination about space debris mitigation rules and the establishment of the international agreement for the guideline.

\section{Acknowledgement}

We like to express great appreciation for the JAXA ISAS in Sagamihara for the technical support as advisory committee member regarding survivability and casualty analysis and consideration. We also like to express our appreciation for team member of JAXA Consolidated Space Tracking and Data Acquisition Department in Tsukuba for 24 hours monitor and reentry prediction work prior to the USERS SEM atmospheric reentry.

\section{References}

1) Matsuoka, T., Kiritani, K., Kunii, Y., Matsuda, S., Takashi, M., Anzai, T., Nakamura, S., Shingu, S. and Ijichi, K. : Unmanned Space Experiment Recovery System (USERS) -System Operation and Re-entry of the Self-return Unmanned Spacecraft, $54^{\text {th }}$ International Aeronautical Congress, 2003, Bremen, Germany, IAC-03-V.3.04

2) Ijichi, K., Kanai, H., Ono, T. and Nakamura, S. : Establishment of the Unmanned Space Experiment Infrastructure for the Wide Range of User's Demands, 57 ${ }^{\text {th }}$ International Aeronautical Congress, 2006, Valencia, Spain, IAC-06-A2.3.06

3) USEF URL www.usef.or.jp 